\title{
Atividades experimentais e simulações computacionais: integração para a construção de conceitos de transferência de energia térmica no ensino médio ${ }^{+*}$
}

Fernanda Teresa Moro ${ }^{1}$

Universidade Regional Integrada do Alto Uruguai e das Missões

Campus de Erechim

Erechim - RS

Italo Gabriel Neide ${ }^{2}$

Márcia Jussara Hepp Rehfeld ${ }^{3}$

Centro Universitário Univates

Lageado - RS

\section{Resumo}

Este trabalho resulta de uma pesquisa qualitativa que foi desenvolvida com estudantes do $2^{\circ}$ ano do Ensino Médio de uma escola particular do município de Erechim, Rio Grande do Sul. A pesquisa buscou investigar as implicações do uso de simulações vinculadas às atividades experimentais na aprendizagem significativa dos estudantes no tópico transferência de energia térmica. Para as atividades experimentais e as simulações computacionais foram planejadas atividades para desenvolver o senso crítico do aluno frente aos experimentos. Os dados analisados apontaram que: a) os estudantes evidenciaram, no questionário semiestruturado dos conhecimentos prévios, antes da intervenção pedagógica, a falta de alguns subsunçores relacionados aos conceitos de propagação da energia térmica, pois não diferenciavam calor e temperatura, o que para muitos significavam sinônimos; b) o material elaborado e proposto nesta prática

\footnotetext{
${ }^{+}$Experimental activities and computational simulations: integration for the construction of concepts of thermal energy transfer in High School

* Recebido: novembro de 2015.

Aceito: agosto de 2016.

1 E-mail: fernandamoro@uricer.edu.br

2 E-mail: italo.neide@univates.br

3 E-mail: mrehfeld@univates.br
} 
mostrou ser potencialmente significativo, pois contribuiu para que houvesse modificação, enriquecimento e elaboração de subsunçores presentes nas estruturas cognitivas de alguns alunos, possibilitando a relação entre o conteúdo e fenômenos que muitas vezes são observados no cotidiano, bem como a diferenciação entre as três formas de transferência de energia térmica e, a existência concomitante delas; c) os estudantes, diante da proposta apresentada, estavam motivados e predispostos para trabalhar com as atividades experimentais e as simulações, realizando estas com entusiasmo e demonstrando interesse, favorecendo a ocorrência da aprendizagem significativa; d) a elaboração dos mapas conceituais e sua apresentação (ao término das atividades propostas) evidenciaram alterações nos subsunçores dos estudantes, bem como apontaram que as atividades experimentais vinculadas às simulações computacionais podem ser uma ferramenta para auxiliar na aprendizagem de alguns conceitos de transferência de energia térmica. Ao final da pesquisa, foi disponibilizado um produto educacional para auxiliar outros professores em suas práticas pedagógicas.

Palavras-chave: Atividades experimentais; Simulações computacionais; Transferência de energia térmica; Ensino de Física; Mapas Conceituais.

\begin{abstract}
This essay is the result of a qualitative research that was developed with students from the second year of high school from a private school of Erechim, Rio Grande do Sul. The research investigates the implications on the use of simulations linked to science activities and experiments creating meaningful learning situations about the topic of thermal energy transfer. Exercises, aiming the development of the students' critical sense in the face of the experiments, were planned based on the experimental activities and the computational simulations. Analyzed data pointed that: a) the students showed, at the semi structured questionnaire of previous knowledge before pedagogical intervention, the lack of some subsumers related to the concepts of thermal energy transfer, since they could not distinguished heat from temperature; The created and proposed material in this practice turned to be potentially significant, because it contributed to modify, enrich and elaborate the subsumers presented in students' cognitive structures, providing the verification of phenomena which mostly were observed in daily life, as well as the differentiation among the three forms of thermal energy transfer and their concomitant existence; $c$ )
\end{abstract}


the students, in face of the required proposal, showed to be motivated and predisposed to work with the experimental activities and simulations, doing them with enthusiasm and showing interest, favoring the occurrence of meaningful learning; d) the conceptual maps, elaborated and presented at the end of the proposed activities, evidenced changings in students' subsumers, as well as they pointed that experimental activities combined with computational simulations can be a tool to help the learning of some concepts of thermal energy transfer. At the end of this research, it was available an educational product to help other teachers with their pedagogical practice.

Keywords: Experimental activities; Computational simulations; Thermal energy transfer; Physics teaching; Conceptual maps.

\section{Introdução}

A prática pedagógica desenvolvida por muitos professores no processo de ensino da Física baseia-se essencialmente na aplicação de fórmulas e apresentação de conceitos e leis. A atividade experimental aliada às simulações pode ser uma possibilidade de transição de um modelo de ensino transmissivo, baseado em cópias e centrado na atividade do professor, para a construção de formas alternativas de ensinar Física.

A inserção de atividades experimentais - reais e virtuais - durante as aulas de Física pode ser uma possibilidade para o professor modificar o ensino baseado única e exclusivamente em aulas expositivas. Nesse sentido, Araújo, Veit e Moreira (2012) enfatizam o uso de tecnologias como um facilitador nos processos de ensino e de aprendizagem na Física, bem como trabalhos descritos na Revista Lusófona de Educação (2013). Por este motivo, entende-se ser relevante a busca de novas práticas pedagógicas que associem o conteúdo com atividades de interesse dos estudantes, atividades estas que aliem a teoria à prática.

Neste trabalho apresentam-se os resultados de uma pesquisa qualitativa que foi desenvolvida com estudantes do $2^{\circ}$ ano do Ensino Médio de uma escola da rede particular do Município de Erechim/RS. Esta pesquisa foi o trabalho de mestrado da autora principal deste trabalho. Buscou investigar as implicações do uso de simulações vinculadas às atividades experimentais na aprendizagem significativa dos estudantes no tópico transferência de energia térmica (condução, convecção e radiação). O problema que embasou a análise foi "Quais as implicações das atividades experimentais e simulações computacionais na aprendizagem significativa dos estudantes no conteúdo de transferência de energia térmica no $2^{\circ}$ ano do Ensino Médio em uma escola da rede particular, na cidade de Erechim/RS?"

Pesquisas como a de Heidmann (2011) destacam que a integração entre atividades experimentais (AE) e atividades computacionais (AC) é importante, pois com as AC os alunos 
interagem com um modelo computacional obtido através da implementação de um modelo teórico. Já com as AE os alunos podem interagir com objetos concretos, reproduzir fenômenos ou comportamentos físicos em estudo. Conforme o autor supracitado o uso integrado das atividades experimentais e das computacionais pode evidenciar importantes diferenças entre teoria e Experiência. A análise das diferenças entre estas atividades tem o potencial de destacar que os modelos teóricos não são cópias da realidade, mas sim representações esquemáticas.

Dorneles (2010) também destaca que a integração entre esses dois tipos de atividades pode propiciar aos alunos uma visão mais adequada sobre os papéis dos modelos teóricos, do laboratório e do computador, promovendo a interatividade e o engajamento dos alunos em seu próprio aprendizado, podendo transformar a sala de aula em um ambiente propício para uma aprendizagem significativa.

\section{Fundamentos teóricos}

As atividades experimentais e as simulações computacionais podem ser uma estratégia para o professor em suas aulas. $\mathrm{O}$ experimento e a simulação constituem-se numa atividade pedagógica desenvolvida pelo aluno que inclui intercaladamente, tarefas teóricas e experimentais, onde o fazer é importante e o refletir para compreender é fundamental. Os novos avanços científicos, bem como suas aplicações práticas e as tecnologias, têm aberto as fronteiras do conhecimento. No mesmo sentido, Brandão, Araújo e Veit (2008, p. 10) destacam:

Estratégias didáticas baseadas na tecnologia e uso de modelos surgem como alternativas para inserção de conteúdos de natureza epistemológica que, imbricados com conteúdo de física, propiciam aos alunos uma visão mais holística sobre a natureza e a construção do conhecimento científico.

Quando se pensa em conhecimento científico é relevante que esse esteja embasado em alguma teoria que propicie a sua construção. Neste sentido, este trabalho tem como referência a teoria cognitivista de Ausubel. Conforme a teoria da aprendizagem significativa de Ausubel (1982) novas ideias e informações podem ser aprendidas e retidas na medida em que conceitos relevantes e inclusivos estejam disponíveis na estrutura cognitiva do indivíduo, comportandose como âncora para novas ideias e conceitos. Uma vez que isso acontece, pode ocorrer a mudança conceitual, substituindo as ideias do senso comum por ideias consolidadas pelo conhecimento científico, consolidando a relação entre ciência, escola e sociedade, possibilitando um ser humano que se coloque como agente atuante e transformador, visto que isso permite ao indivíduo o conhecimento cada vez maior do seu universo físico, bem como os fenômenos que nele acontecem. De acordo com esta ideia Moreira (2001, p. 35) menciona:

Como poderia o homem situar-se no mundo se não organizasse suas experiências? $O$ que impressiona é o sentido, percebido e compreendido, passando, constantemente e 
dinamicamente, por um processo psicológico de elaboração e organização denominado aquisição de conceitos. É esse conjunto próprio de conceitos constantemente adquirido e reelaborado que permite ao homem situar-se no mundo e decidir como agir.

Moreira e Ostermann (1999) destacam que a ideia mais importante da teoria de Ausubel e suas possíveis implicações para o ensino e a aprendizagem é aquilo que o aprendiz já sabe. Precisa-se determinar isso e ensinar de acordo. Entende-se, portanto, que no trabalho embasado na teoria de Ausubel é imprescindível que o professor verifique os conhecimentos prévios dos alunos referentes ao conteúdo que se está trabalhando, servindo de âncora para as novas informações. Borges (2002, p. 301) destaca que:

Para facilitar a aprendizagem e compreensão de conceitos com a utilização de atividades experimentais recomenda-se um planejamento cuidadoso que considere as ideias prévias dos estudantes a respeito da situação estudada, o tempo necessário para completar a atividade, as habilidades requeridas e aspectos ligados à segurança.

Quando se fala em aprendizagem significativa, além dos conhecimentos prévios do aluno, outro fator importante é que os materiais utilizados sejam potencialmente significativos. As atividades experimentais e as simulações computacionais podem ser exemplos de materiais potencialmente significativos que estão ao alcance do professor. Além disso, o uso de tecnologias e atividades experimentais durante as aulas pode permitir que os estudantes estejam predispostos a trabalhar de modo ativo, na busca de soluções para os problemas que lhes são propostos. É importante salientar que, de acordo com os Parâmetros Curriculares Nacionais (PCNs):

A utilização de recursos como o computador e a calculadora pode contribuir para que o processo de ensino e aprendizagem se torne uma atividade experimental mais rica, sem riscos de impedir o desenvolvimento do pensamento, desde que os alunos sejam encorajados a desenvolver seus processos metacognitivos e sua capacidade crítica e o professor veja reconhecido e valorizado o papel fundamental que só ele pode desempenhar na criação, condução e aperfeiçoamento das situações de aprendizagem (BRASIL, 1999, p. 45).

Os PCNs (BRASIL,1999, p. 45) destacam "longe da ideia de que o computador viria substituir o professor, seu uso vem, sobretudo, reforçar o papel do professor na preparação, condução e avaliação do processo de ensino e aprendizagem". Deste modo, faz-se necessário repensar o ensino para que este concilie o pensar ao aprender fazendo, e que também possibilite o resgate de metodologias aliadas às tecnologias. Conforme Dorneles, Araújo e Veit (2006), a predisposição para aprender é uma das condições para que ocorra a aprendizagem significativa.

É neste sentido que o trabalho com recursos computacionais pode ter potencial de as- 
sociação, rompendo com a visão de compartimentos fechados das disciplinas do currículo escolar. Conforme Lévy (2008) as tecnologias são recursos que criam alternativas metodológicas rompendo com o formalismo das disciplinas, que fragmenta e cristaliza o conhecimento em compartimentos fechados. Brandão, Araújo e Veit (2008, p. 12) afirmam:

\begin{abstract}
O computador, visto como uma ferramenta didática no auxílio da aprendizagem pode fornecer oportunidades ímpares para a contextualização, visualização e apresentações das mais diversas situações físicas que possam dar sentido ao conceito físico que esteja sendo trabalhado pelo professor.
\end{abstract}

As aulas de Física nas escolas, de um modo geral, consistem em resoluções de listas de exercícios e, muitas vezes, apenas a leitura de textos que se apresentam nos livros didáticos adotados. Diante da realidade defrontada no ensino da Física, urge a necessidade da busca de novas práticas, que aliem o conteúdo com ao dia-a-dia dos estudantes, o que justifica o problema desta pesquisa: quais as implicações das atividades experimentais e simulações computacionais na aprendizagem significativa dos estudantes no conteúdo de transferência de energia térmica no $2^{\circ}$ ano do Ensino Médio em uma escola da rede particular, na cidade de Erechim/RS? Poder-se-ia dizer que uma sugestão na busca por estas novas práticas está na integração entre a atividade experimental e as tecnologias (softwares, simuladores) como uma estratégia no ensino de Física, que foi o ponto de análise desta pesquisa. Araújo e Abib (2003, p. 176) declaram que:

[...] o uso de atividades experimentais (reais ou virtuais) como estratégia de ensino de Física tem sido apontado por professores e alunos como uma das maneiras mais frutíferas de se minimizar as dificuldades de se aprender e de se ensinar Física de modo significativo e consistente.

A partir dessa afirmação, reforça-se a importância da utilização de atividades experimentais aliadas ao uso de tecnologias durante as aulas de Física no Ensino Médio. Araújo, Veit e Moreira (2012) destacam que nas aulas convencionais de Física em cursos de nível médio e superior observam-se professores que associam o aprendizado a receitas de resolução de problemas, tendo equações como foco. Os autores ainda mencionam que docentes abolem praticamente as atividades experimentais, que podem contribuir para uma compreensão adequada do conteúdo. Conforme os autores supracitados um desafio que se apresenta é como representar fenômenos reais por meio de modelos, conceitos, trabalho colaborativo, formulação e teste de hipóteses para a sala de aula.

As atividades experimentais investigativas representam uma estratégia para permitir que os alunos ocupem uma posição mais ativa no processo de construção do conhecimento e que o professor passe a ser mediador ou facilitador desse processo. $\mathrm{O}$ professor deve ter a capacidade de proporcionar a participação dos estudantes em todas as etapas da investigação. Suart e Marcondes (2008, p. 2) afirmam: 
[...] se o estudante tiver a oportunidade de acompanhar e interpretar as etapas da investigação, ele possivelmente será capaz de elaborar hipóteses, testá-las e discutilas, aprendendo sobre os fenômenos químicos estudados e os conceitos que os explicam, alcançando os objetivos de uma aula experimental, a qual privilegia o desenvolvimento de habilidades cognitivas e o raciocínio lógico.

É nesse contexto que esta pesquisa foi inserida, cuja proposta foi utilizar atividades experimentais e simulações para uma melhor compreensão dos fenômenos relacionados à transferência de energia térmica. Muitas simulações computacionais podem ser utilizadas aliadas às atividades experimentais durante as aulas de Física, em especial, no tópico de Termologia, como por exemplo, o Energy $2 D^{4}$ e no PhET ${ }^{5}$, que foi utilizado nesta pesquisa.

Cabe aqui destacar que o termo "calor" em Física, conforme Young e Freedman (2006), sempre se refere a uma transferência de energia de um corpo ou sistema para outro em virtude de uma diferença de temperatura existente entre eles, nunca indica a quantidade de energia contida em um sistema particular. Os autores supracitados ainda destacam que A emissão de radiação ocorre em corpos a qualquer temperatura diferente de $0 \mathrm{~K}$, independentemente da temperatura dos corpos à sua volta.

Silva, Laburú e Nardi (2008) salientam que muitos livros didáticos, tanto da educação básica, quanto do Ensino Superior, apresentam distorções quanto ao conceito de calor. Conforme estes autores seria melhor usar a palavra calor apenas em referência a um método de transferência de energia e, quando essa transferência se completasse, referir-se à quantidade total de energia transmitida. Nesse sentido, um corpo não tem calor, tem energia; mas quando se transfere parte dessa energia numa situação de diferença de temperatura, refere-se a ela como a quantidade de calor transferida, compreendendo-se, portanto, que o corpo teve um acréscimo de energia em forma de calor. Conforme Bucussi (2007), condução, convecção e radiação são formas de propagação (ou transferência) de energia térmica.

\section{Caminhos da pesquisa}

Nos processos de ensino e de aprendizagem deve haver uma situação de encontro, de diálogo, em que professor e aluno se colocam dispostos a aprender. Partindo das vivências profissionais da prática de um dos autores, surgiu o questionamento: Como articular atividades experimentais e simulações por computadores, para a compreensão das formas de transferência de energia térmica?

Buscando resposta a esta inquietação, traçaram-se os seguintes objetivos para a pesquisa: a) Verificar os conhecimentos prévios dos estudantes relacionados às formas de propa-

\footnotetext{
4 Disponível em: <http://energy.concord.org/energy2d/>.

5 Disponível em: <https://phet.colorado.edu/pt_BR/>.
} 
gação de energia térmica (condução, convecção e radiação), bem como suas aplicações em situações do cotidiano; b) Desenvolver o conteúdo de transferência de energia térmica por meio da integração entre as atividades experimentais e simulações computacionais durante as aulas de Física no $2^{\circ}$ ano do Ensino Médio; c) Investigar se as atividades desenvolvidas são potencialmente significativas para a aprendizagem dos alunos sobre elementos importantes da Termologia (formas de transferência de energia térmica).

Para atingir tais objetivos, foram realizadas três atividades experimentais sobre condução, convecção e radiação, na própria sala de aula, concomitantes com a abordagem teórica dos conteúdos pelo pesquisador. A teoria dos conteúdos e conceitos abordados permearam as atividades experimentais. A Fig. 1 apresenta os equipamentos para as três atividades experimentais.

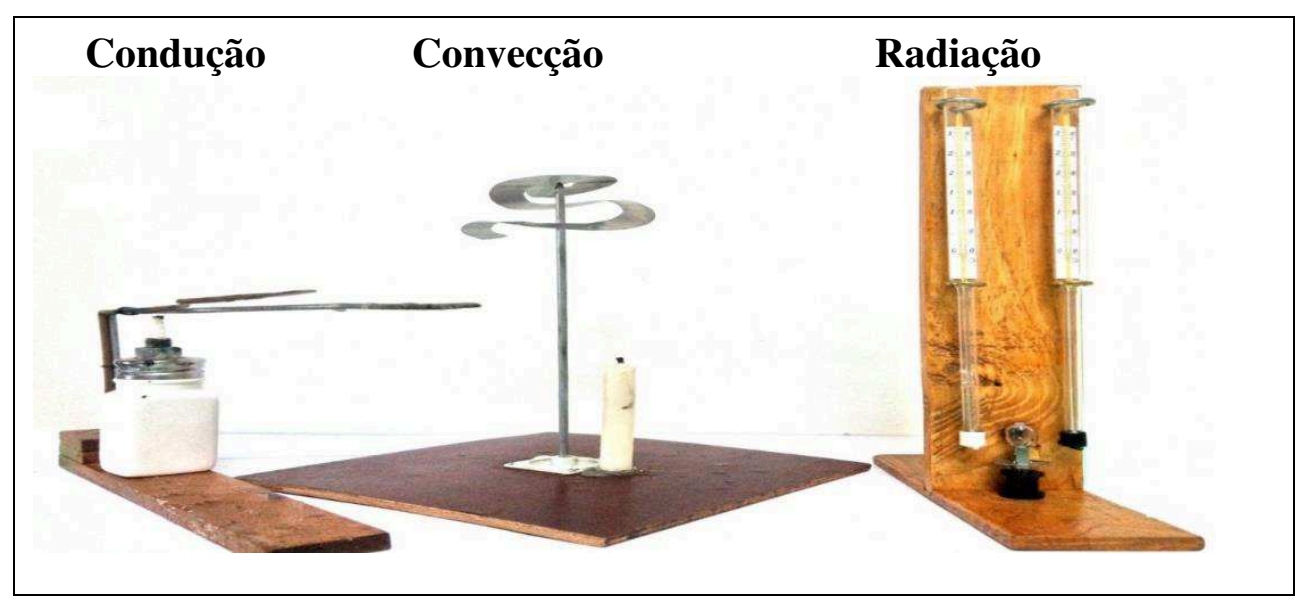

Fig. 1 - Esquema das atividades experimentais construídas pelo autor (Fonte: Os autores, 2015).

A primeira atividade experimental refere-se à condução térmica, onde os estudantes devem observar quais pontos de cera derretem primeiro. Um dos fios é cobre e outro de ferro, ambos de mesma espessura e com pontos de cera simétricos. Na atividade seguinte que aborda a convecção térmica os estudantes devem observar que quando a chama da vela está acesa a hélice superior movimenta-se e, ao apagá-la, cessa esta movimentação (o que demonstra a presença de correntes de convecção). Já na última atividade, os bulbos dos termômetros são envolvidos em uma cápsula branca e outro em uma cápsula preta. Quando a lâmpada (farol de carro) é ligada aquecerá estes termômetros principalmente por radiação. Os estudantes devem observar que corpos escuros absorvem a maior parte da radiação e, consequentemente, no mesmo intervalo de tempo, elevam a sua temperatura mais do que comparado às cores claras.

Ao longo da efetivação da atividade experimental foi adotado um diário de bordo que conforme Denzin e Lincoln (2006) é uma técnica própria da investigação qualitativa, onde constaram as observações do pesquisador, fotos e os trabalhos dos alunos. A Fig. 2 apresenta 
os estudantes durante as três atividades experimentais realizadas. Cabe destacar que os 35 estudantes que participaram da pesquisa receberam o Termo de Consentimento Livre e Esclarecido.

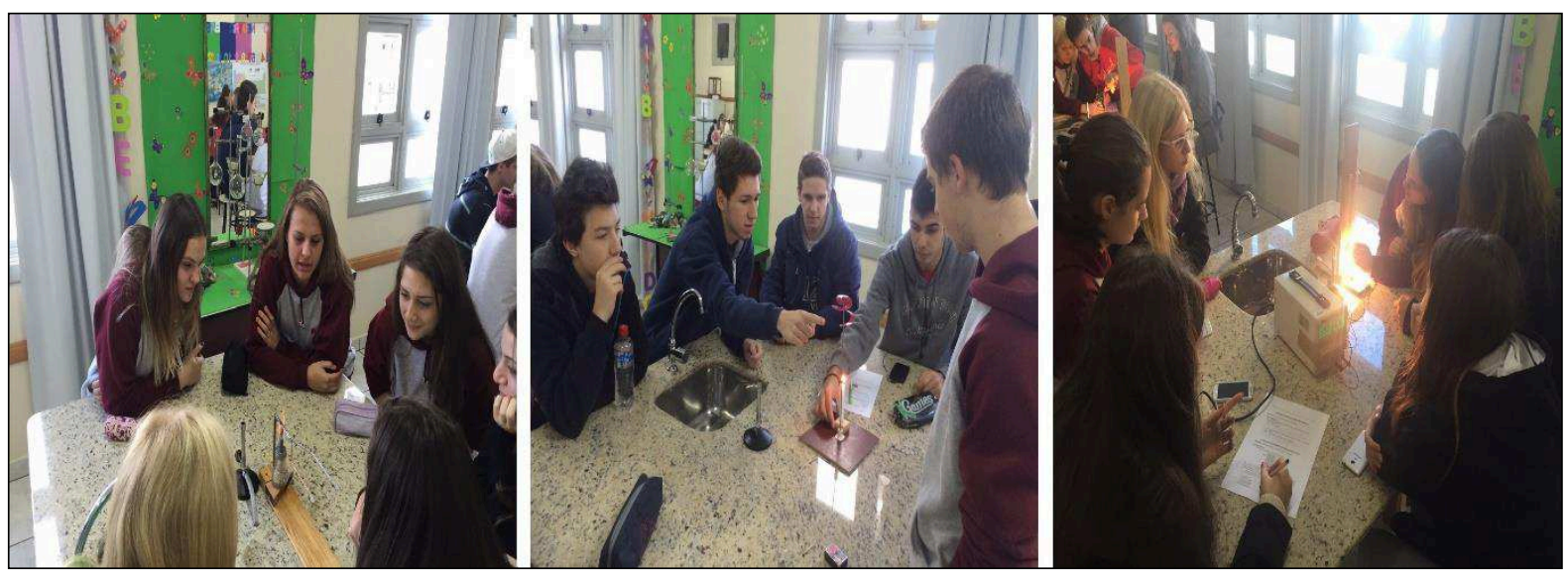

Fig. 2 - Alunos durante as atividades experimentais propostas (Fonte: Os autores, 2015).

É importante destacar que as atividades experimentais foram planejadas buscando sua integração com as simulações disponíveis, enfatizando as relações entre as atividades realizadas com material concreto e as explorações advindas das simulações do Energy $2 D$ - Interactive Heat Transfer Simulations for Everyon do National Science Foundation-The Concord Consortium (EUA) ${ }^{6}$ e do PhET Interactive Simulation, da Universidade do Colorado (EUA) 7 . Tanto as simulações do PhET quanto as do Energy $2 D$ são gratuitas.

O Energy $2 D$ apresenta simulações baseadas em pesquisas de física computacional. É um programa de simulação interativa de modelos que envolvem as formas de transferência de energia térmica por condução, convecção e radiação. É um programa que é executado de maneira rápida na maioria dos computadores. Já o PhET, conforme Arantes, Miranda e Studart (2010) é um programa da Universidade do Colorado que pesquisa e desenvolve simulações na área de ensino de ciências e as disponibiliza em seu portal para serem usadas on-line ou serem baixadas gratuitamente pelos usuários que podem ser alunos, professores ou mesmo curiosos. Nas simulações, procura-se conectar fenômenos diários com a ciência, oferecendo modelos fisicamente corretos de maneira acessível.

Neste trabalho, foram utilizadas três simulações computacionais: para a condução e a convecção duas simulações do Energy $2 D$ e para a radiação, uma simulação do $P h E T$. A Fig. 3 apresenta uma das simulações que foi trabalhada, evidenciando a transferência de energia térmica por convecção.

\footnotetext{
6 Disponível em: <http://energy.concord.org/energy2d/>.

${ }^{7}$ Disponível em <https://phet.colorado.edu/pt_BR/>.
} 


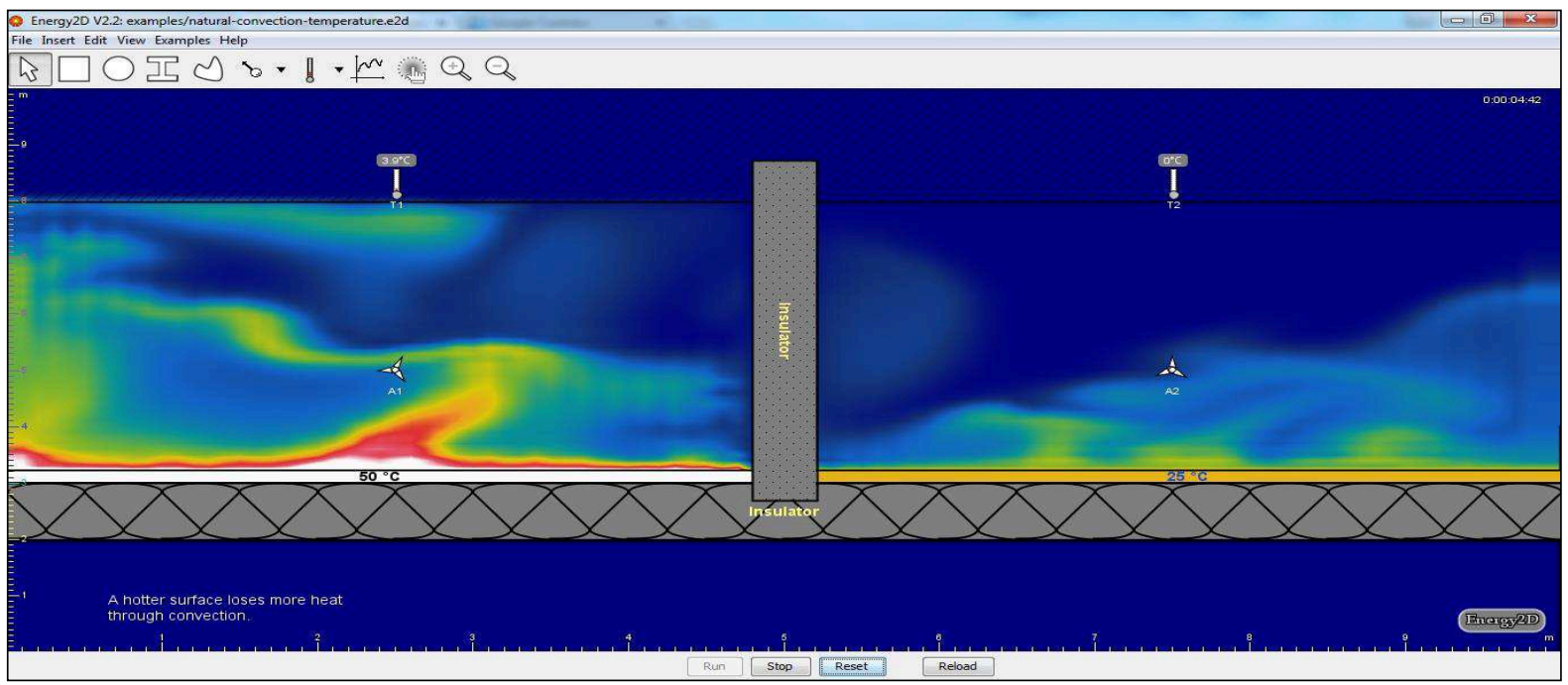

Fig. 3 - Transferência de energia térmica por convecção em diferentes materiais (Energy2D, 2015).

A escolha desta simulação justifica-se pelo fato do estudante poder observar, através do recurso de cores, a formação das correntes de convecção, devido à diferença de temperatura nas camadas de ar, bem como o sentido desta movimentação, o que na atividade experimental apenas causa movimentação da hélice, sem destacar que o ar frio desce e o quente sobe. Já na Fig. 4 pode-se observar a simulação do Energy2D referente à condução térmica. Nesta simulação, através do recurso de cores e do termômetro, é possível verificar a condutibilidade térmica em materiais distintos, como a madeira e o metal.

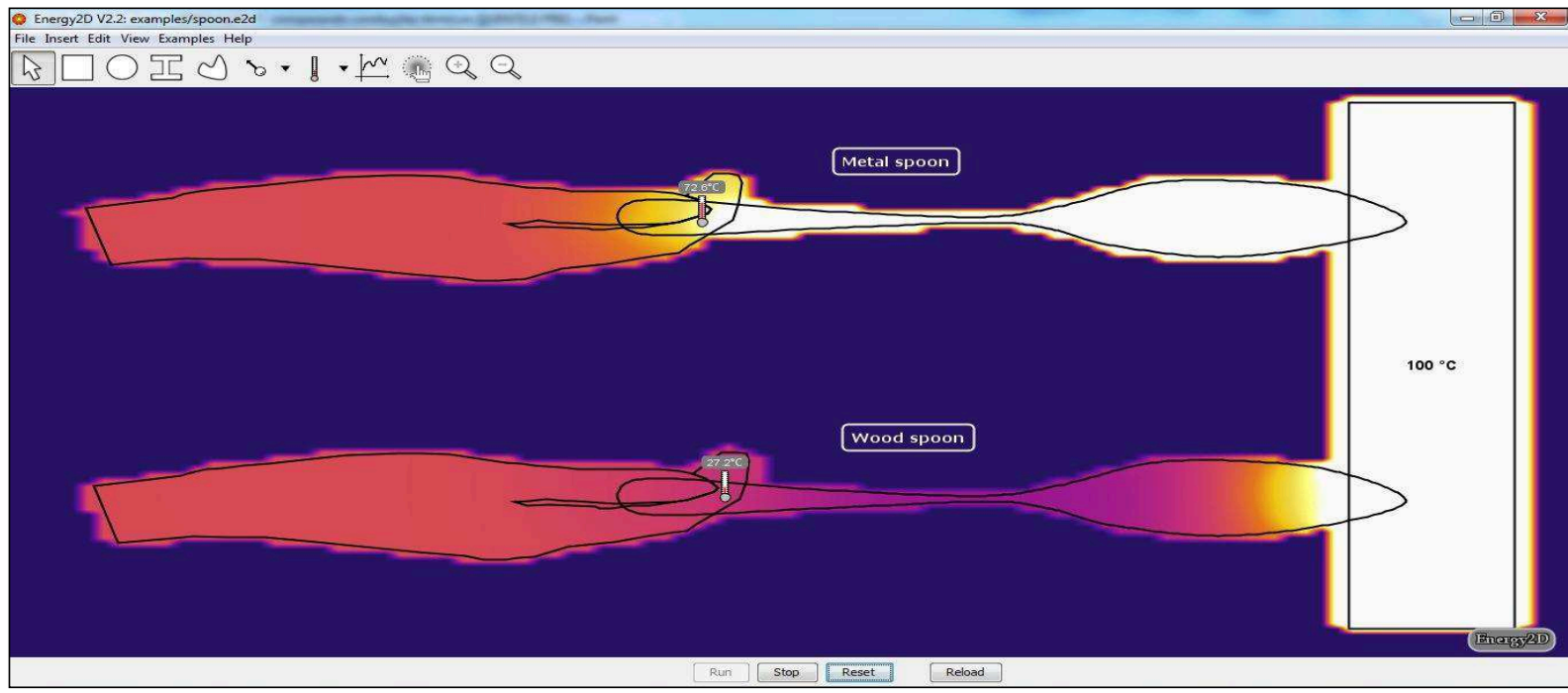

Fig. 4 - Simulação envolvendo a propagação de calor por condução (Energy2D).

A última simulação computacional escolhida serviu para complementar a atividade de radiação realizada com os estudantes. Para esta atividade foi escolhida a simulação do PhET utilizada na intervenção. Nesta simulação os estudantes podem alterar os objetos e relacionar 
com diferentes formas de energia (cinética, química, térmica). A Fig. 5 ilustra a simulação.

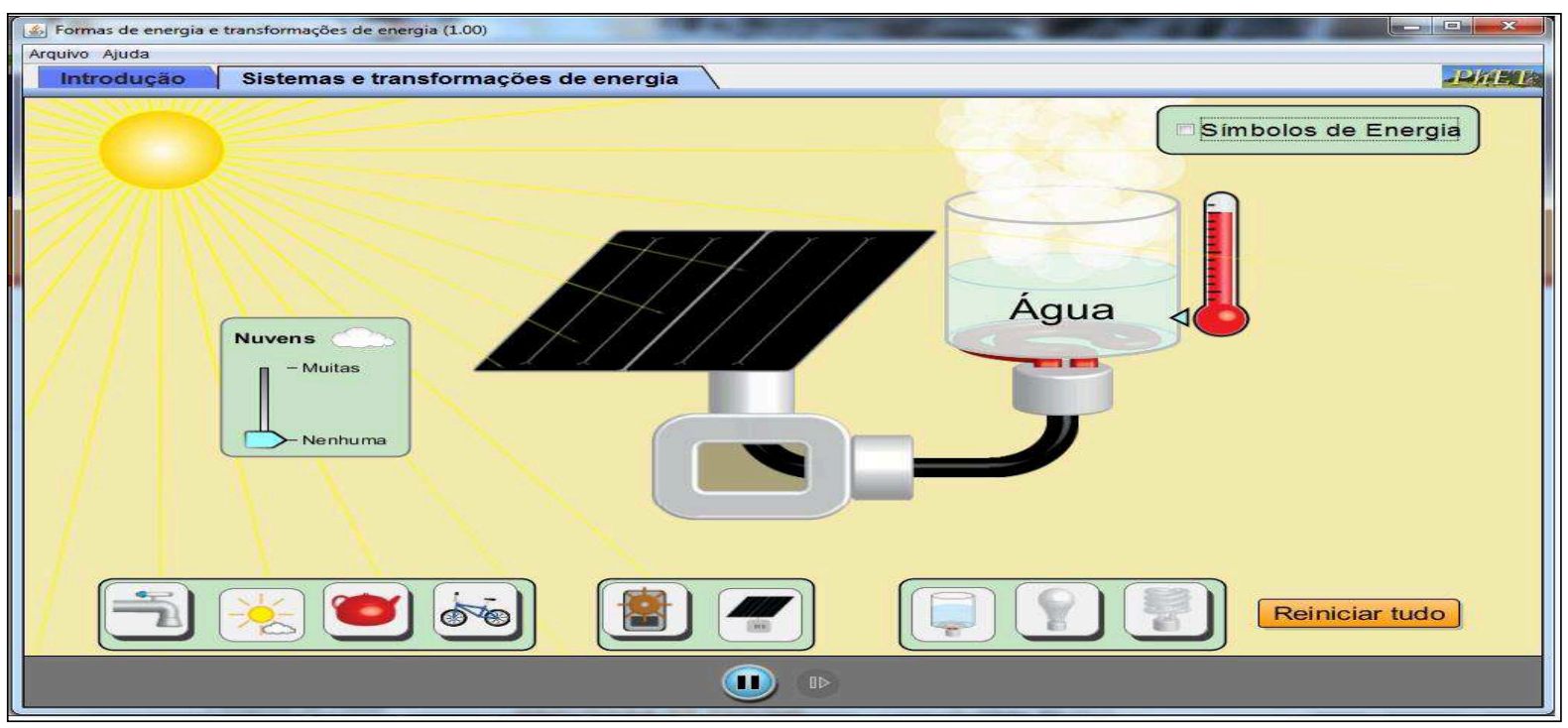

Fig. 5 - Transferência de energia térmica por radiação (PhET Interactive Simulations)

As atividades de simulação são importantes e se justificam tendo em vista que a observação/discussão de algumas particularidades de fenômenos físicos só são possíveis de serem desenvolvidas com recursos computacionais, pois pode-se reverter qualquer tipo de processo controlando a velocidade com que o processo acontece. O estudante tem autonomia de parar ou reiniciar no momento em que entender ser mais oportuno, podendo também, alterar parâmetros.

Araújo, Veit e Moreira (2008) destacam que uma das vantagens do uso de atividades computacionais está na capacidade de proporcionar a interação do aluno com experimentos virtuais, substitutos de experimentos reais caros ou perigosos. Medeiros e Medeiros (2002) também ressaltam o fato das atividades computacionais fornecer múltiplas representações simultâneas de determinado fenômeno físico. Zacharias e Anderson (2003) destacam a importância da integração entre as atividades experimentais e as atividades computacionais, onde o aluno pode usufruir das potencialidades de ambas atividades.

Finalmente, os estudantes em duplas, elaboraram um Mapa Conceitual (utilizando o programa Cmap Tools) que foi, juntamente com o diário de bordo, filmagens, atividades experimentais, simulações computacionais e questionário semiestruturado, mais um instrumento para auxiliar a averiguar se a proposta metodológica aplicada foi potencialmente significativa para os estudantes. Conforme Moreira (1983, p. 1):

Mapas conceituais são diagramas de significados, de relações significativas; de hierarquias conceituais, se for o caso. Isso também os diferencia das redes semânticas que não necessariamente se organizam por níveis hierárquicos e não obrigatoriamente incluem apenas conceitos. Mapas conceituais também não devem ser confundidos com mapas mentais que são associacionistas, não se ocupam de relações entre 
conceitos, incluem coisas que não são conceitos e não estão organizados hierarquicamente. Não devem, igualmente, ser confundidos com quadros sinópticos que são diagramas classificatórios. Mapas conceituais não buscam classificar conceitos, mas sim relacioná-los e hierarquizá-los.

Para compreender mapas conceituais, é oportuno apresentar em um mapa conceitual os conceitos centrais que devem estar presentes. A Fig. 6 apresenta diagrama dos principais elementos que podem fazer parte de um mapa conceitual.

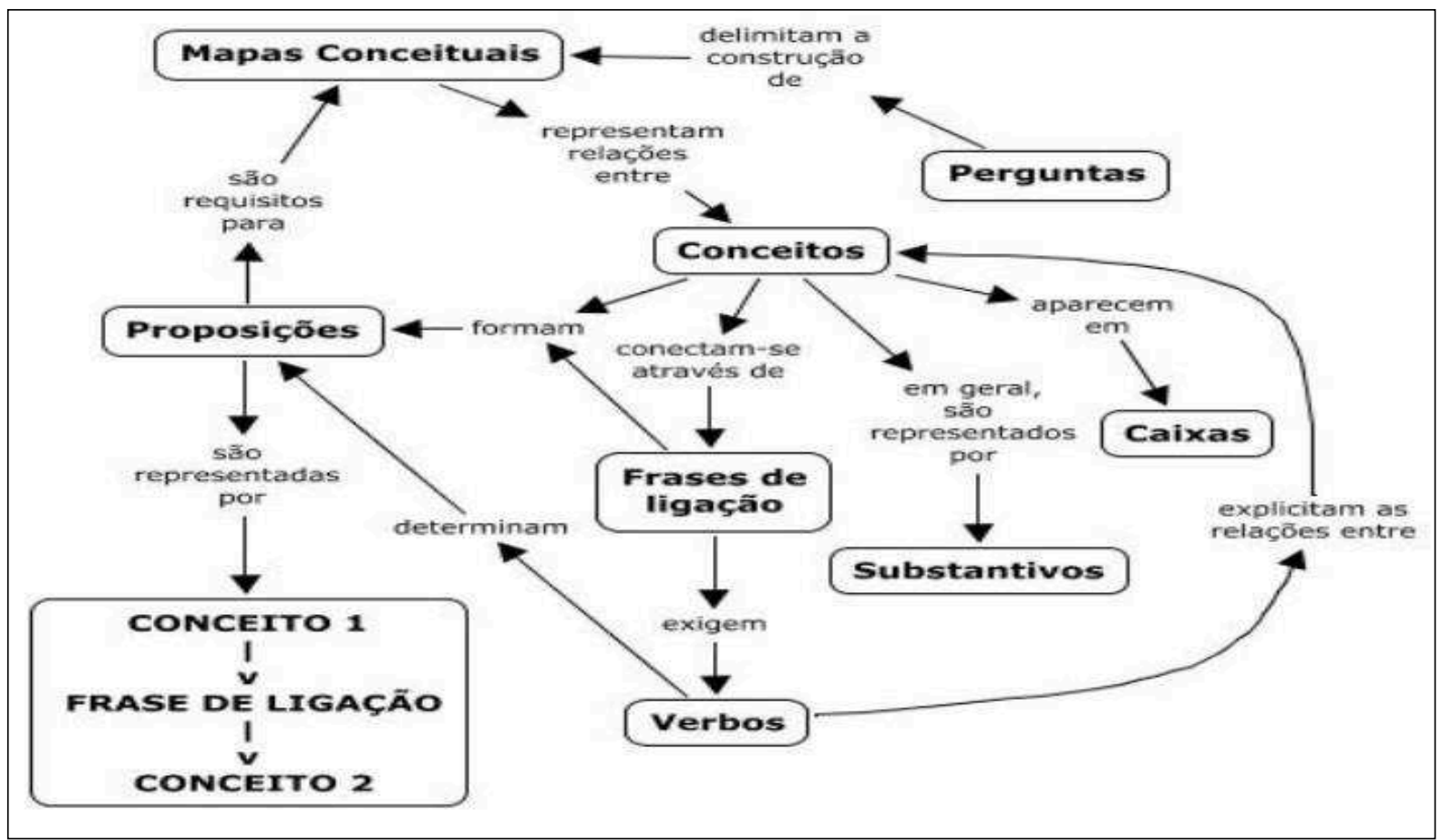

Fig. 6 - Principais elementos de um mapa conceitual (DUTRA et al., 2006, p. 26).

\section{Discussão dos resultados}

Buscando indícios de aprendizagem significativa, os estudantes elaboraram, em duplas, um mapa conceitual que abordasse o que foi estudado. Os mapas conceituais podem ser utilizados como instrumento didático e como instrumento de avaliação, no sentido de obter informações sobre o tipo de estrutura o aluno vê para um dado conjunto de conceitos. Segundo Moreira (2006) na avaliação através de mapas conceituais a principal ideia é a de avaliar o que o aluno sabe em termos conceituais, como ele estrutura, hierarquiza, diferencia, relaciona, discrimina, integra, conceitos de uma determinada unidade de estudo.

Desta forma, pensou-se o uso dos mapas conceituais e sua apresentação ao término da intervenção, buscando uma visualização de conceitos e relações hierárquicas entre os mesmos, como uma maneira de exteriorizar o que o aluno já sabe, procurando indícios de aprendizagem significativa. Os mapas construídos pelos estudantes foram analisados, buscando indícios de 
aprendizagem significativa. Treze dos dezoito mapas construídos apresentaram a estrutura vertical, como descrita anteriormente. Os outros cinco mapas elaborados pelos estudantes apresentaram a ideia de teia de aranha. Na sequência serão apresentados os resultados de três mapas conceituais elaborados pelos estudantes nesta pesquisa. A Fig. 7 apresenta um dos mapas conceituais elaborado por uma das duplas.

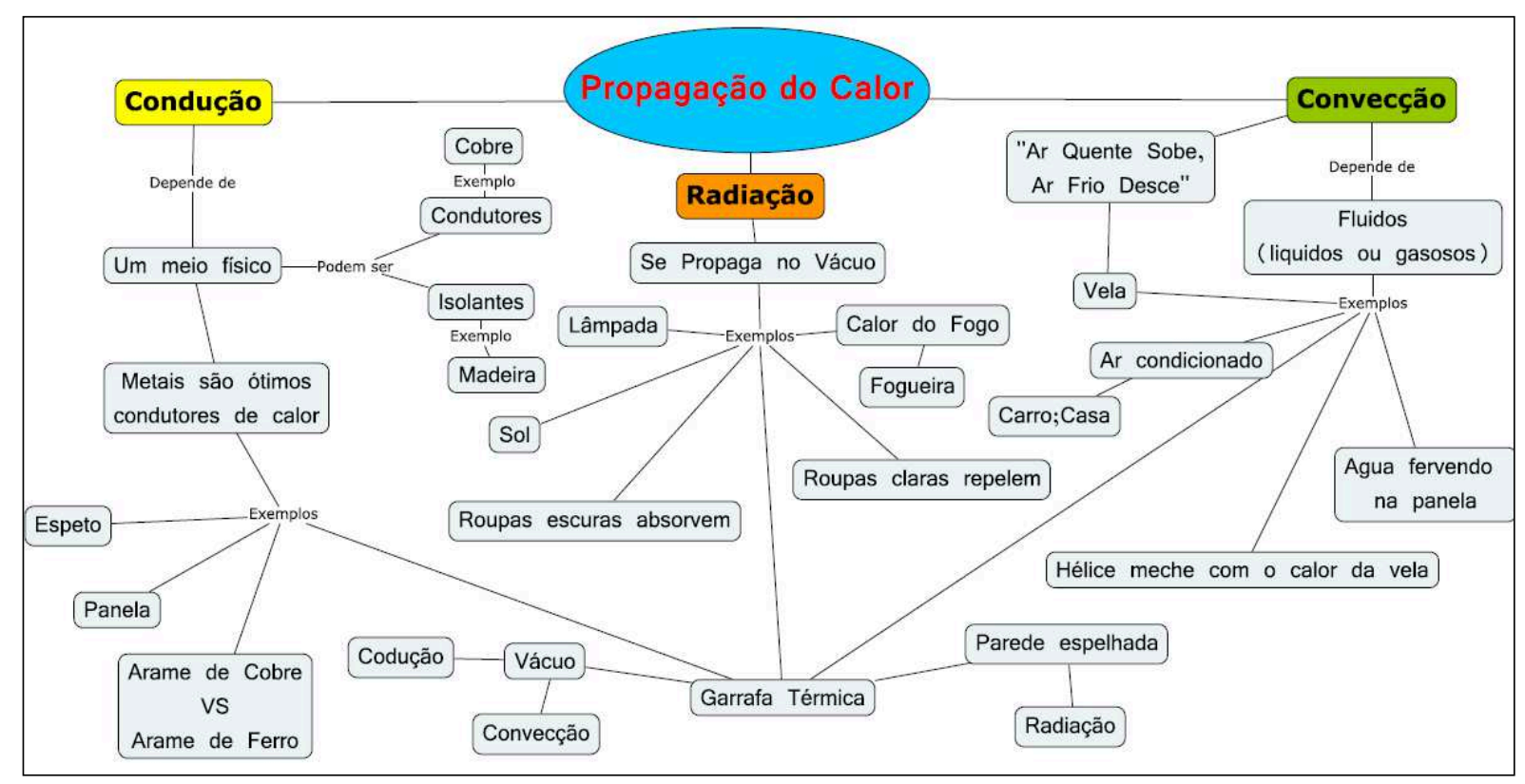

Fig. 7 - Mapa conceitual construído por uma das duplas (Fonte: Os autores, 2015).

Percebe-se, por meio deste mapa conceitual, que os estudantes relacionaram os exemplos com as atividades realizadas, tanto as experimentais quanto as simulações, ao citarem no canto inferior esquerdo o arame de cobre e o arame de ferro, bem como a hélice que girava com o calor da vela (canto inferior direito do mapa), materiais usados nas atividades experimentais realizadas no Laboratório de Física da escola. Conforme a teoria de Ausubel (2003) há indícios de diferenciação progressiva e de reconciliação integradora que podem ser observados na ligação entre os três modos de propagação da energia térmica ilustrados com a garrafa térmica (que não foi utilizada nos experimentos). Logo, pode ser um indício da diferenciação progressiva e da reconciliação integradora que Moreira (2006, p. 40) define como:

A diferenciação progressiva é o processo de atribuição de novos significados a um dado subsunçor (um conceito ou uma proposição, por exemplo) resultante da sucessiva utilização desse subsunçor para dar significado a novos conhecimentos. [ ] A reconciliação integradora, ou integrativa, é um processo da dinâmica da estrutura cognitiva, simultâneo ao da diferenciação progressiva, que consiste em eliminar diferenças aparentes, resolver inconsistências, integrar significados, fazer superordenações. 
Percebe-se a existência de exemplos e relações com o cotidiano, como a garrafa térmica, bem como o resgate das observações realizadas nas atividades experimentais e nas simulações computacionais (no alto à esquerda do mapa quando os estudantes escrevem que os metais são bons condutores, interligando esse conector com os arames de ferro e cobre) e também na parte central do mapa (roupas escuras absorvem e claras repelem - referenciando na apresentação oral deste mapa que se basearam na atividade com os termômetros e na simulação que apresentava um coletor solar - cor escura).

Porém, é conveniente destacar que, alguns mapas apresentam eventuais erros linguísticos, estruturais e hierárquicos. Por exemplo, a palavra "Condução" na caixa ligada à "garrafa térmica" está escrita incorreta; faltam várias ligações entre caixas, também não faz sentido, numa estrutura hierárquica de um mapa conceitual que os conceitos Condução, Convecção e Radiação apareçam no início e no fim do mapa.

Conforme Moreira (2005), a construção de um mapa conceitual implica atribuição de significados idiossincráticos, o que corresponde afirmar que cada aluno representa seu mapa conceitual e não existe um único mapa conceitual correto.

Outro mapa apresentado pelos estudantes faz referência à condução que pode ocorrer em metais, uma vez que são melhores condutores de energia térmica, exemplificado com colheres, espetos e panelas. Percebe-se o formato de teia de aranha na construção desse mapa. $\mathrm{O}$ mapa da Fig. 8 apresenta várias falhas hierárquicas estruturais, mas revelando algumas conexões importantes de aprendizagem dos alunos.

A partir da análise deste mapa percebem-se indícios da diferenciação de significados e da reconciliação integradora, principalmente quando os estudantes relacionam os experimentos e simulações realizadas com outras situações que apresentam estes fenômenos no seu dia a dia (geladeira, ar condicionado, brisas, diferenças de densidade). Isto vem ao encontro do que Moreira (2011, p. 22) destaca:

Quando aprendemos de maneira significativa temos que progressivamente diferenciar significados dos novos conhecimentos adquiridos a fim de perceber diferenças entre eles, mas é preciso também proceder a reconciliação integradora. Se apenas diferenciarmos cada vez mais os significados, acabaremos por perceber tudo diferente. Se somente integrarmos os significados indefinidamente, terminaremos percebendo tudo igual. Os dois processos são simultâneos e necessários à construção cognitiva, mas parecem ocorrer com intensidades distintas [ ].

A Fig. 8 apresenta o mapa conceitual analisado anteriormente.

Outros alunos representaram mapas como um fluxograma, nos quais "as informações estão organizadas de uma maneira lógica e sequencial” (TAVARES, 2007, p. 75), conforme pode ser visto no mapa $\mathrm{M}^{15}$. A Fig. 9 ilustra um exemplo de mapa conceitual em forma de fluxograma, não havendo conectores entre os modos de propagação da energia térmica. 


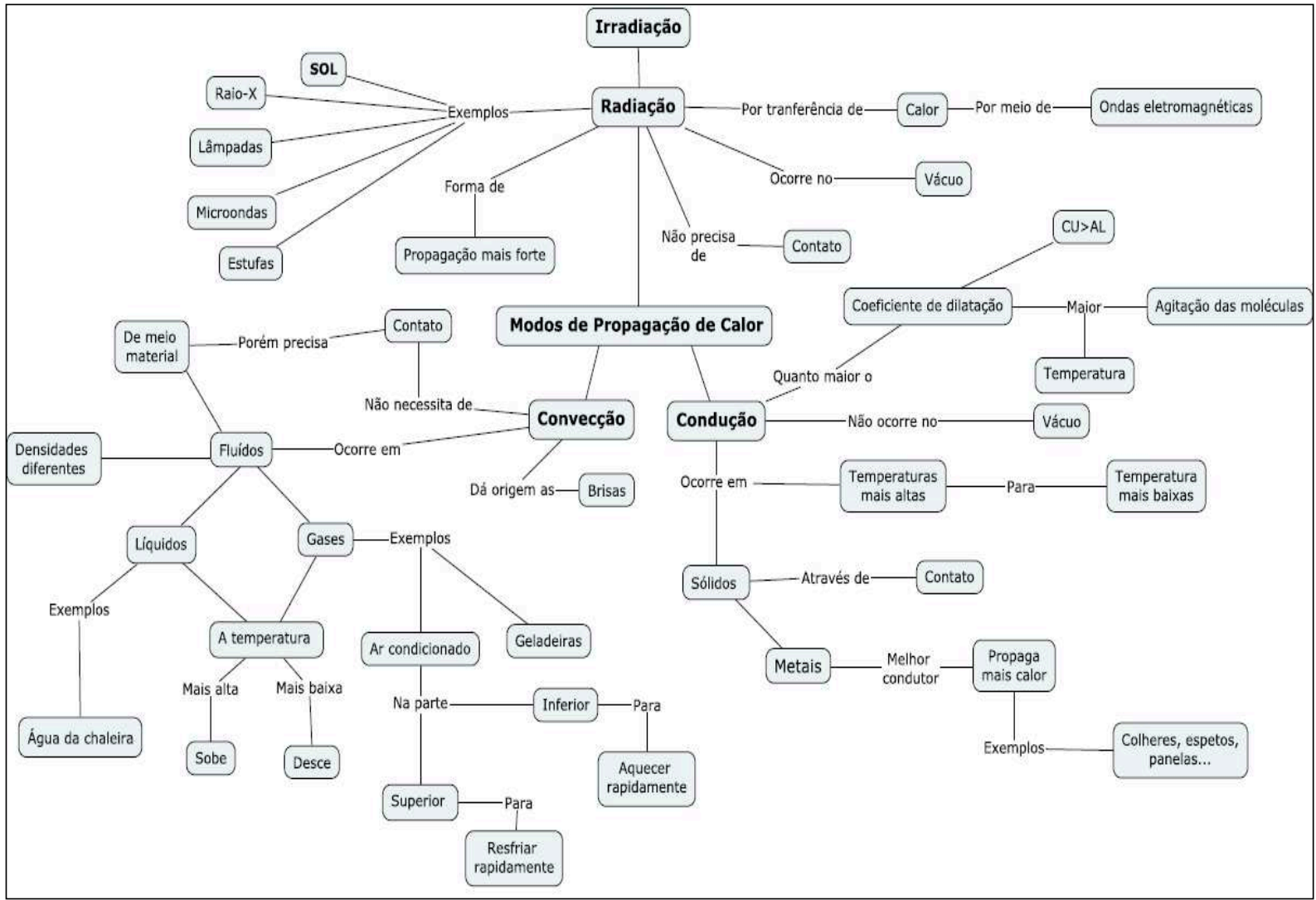

Fig. 8-Mapa conceitual M $M^{11}$ elaborado pelos estudantes (Fonte: Os autores, 2015).

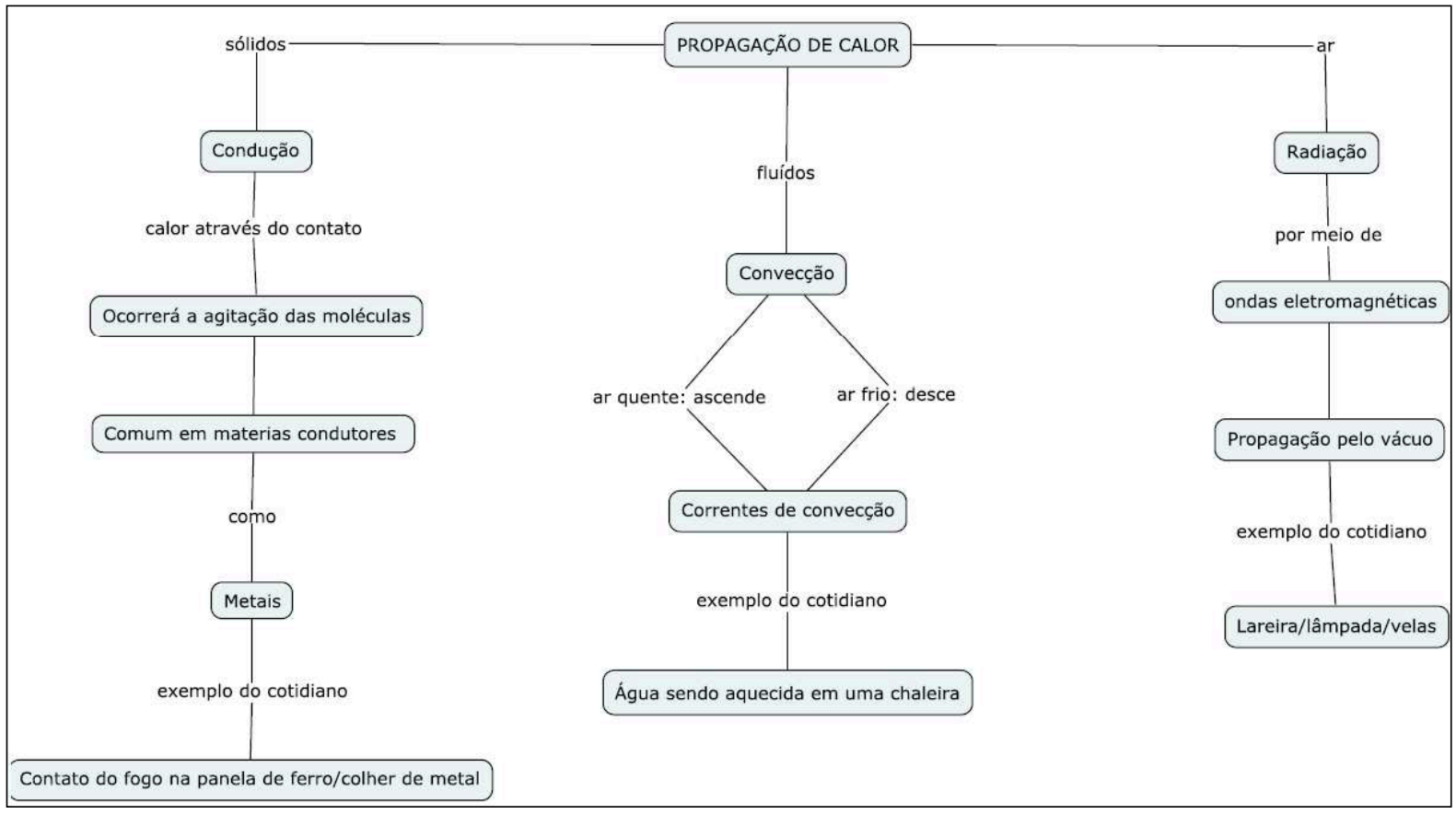

Fig. 9 - Mapa conceitual $M^{15}$ (Fonte: Os autores, 2015). 
Analisando o conjunto de 18 mapas conceituais, verifica-se que, conforme Moreira (2005) e Tavares (2007), a aprendizagem implica atribuição de significados idiossincráticos e os mapas traçados pelos alunos evidenciaram isto. De uma forma geral, os mapas iniciais, apresentaram conceitos e conectores importantes quando se trabalha as formas de propagação da energia térmica. Alguns estudantes mencionaram que ouvem, durante os noticiários de previsão do tempo, termos errados, confundindo calor e temperatura. Um dos estudantes mencionou: "É como aquela velha história: você vai na farmácia e sobe na balança para ver sua massa e não o seu peso, como ouvimos muitos falar!". Isso evidencia que alguns estudantes modificaram suas concepções iniciais, o que pode ser um indício de reconciliação integradora, que conforme Moreira (2006) faz parte do processo de aprendizagem significativa, resultando num delineamento explícito de similaridades e diferenças entre ideias correlatas.

Ao comparar os resultados do questionário semiestruturado com as respostas das atividades experimentais e das simulações, bem como com os mapas conceituais construídos, observa-se que novos conceitos acerca da propagação da energia térmica foram elaborados, bem como pode-se observar uma transição conceitual nas estrutura cognitiva dos alunos, de forma que para alguns isso ocorreu no sentido de enriquecimento, e para outros de obliteração, essa sendo um processo natural (MOREIRA, 2008, p. 29):

A assimilação obliteradora é uma continuidade natural da assimilação (aprendizagem subordinada). Organizadores prévios podem ser usados para "resgatar", "ativar", "recuperar" esse conhecimento obliterado. É possível também que o professor saiba, de sua experiência, que o aluno não perceberá facilmente que o novo material de aprendizagem está relacionado com conhecimentos prévios significativos existentes em sua estrutura cognitiva. Certamente, organizadores prévios poderão ajudar muito na percepção dessa relacionabilidade.

O questionário utilizado foi estruturado com seis perguntas relacionadas aos modos de propagação da energia térmica, buscando suas aplicações em situações vivenciais. As questões 1 e 2 investigavam os conceitos de calor e de temperatura. Já as questões 3 e 4 apresentavam situações do cotidiano (bolsa de água quente que esquenta o pé, camisetas claras e escuras expostas ao Sol e mão queimando em um espeto de churrasco que está no fogo.

Analisando algumas respostas percebem-se indícios de ideias que têm potencial de estar cientificamente aceitas em algum momento, após o trabalho com o material potencialmente significativo. Os termos usados foram "roubar calor" e "energia transferida do mais quente para o mais frio" o que pode demonstrar ideias de transferência de energia térmica. Os conhecimentos prévios, de acordo com Ausubel (2003), são um dos requisitos para que ocorra a aprendizagem significativa. A Fig. 10 destaca as respostas de alguns estudantes $\left(\mathrm{E}^{8}, \mathrm{E}^{25}\right.$ e $\left.\mathrm{E}^{33}\right)$.

Estas respostas podem evidenciar relações com o conteúdo como transformação de uma forma de energia em outra (cinética em térmica, quando há atrito por exemplo - conteúdos 
já abordados neste ano letivo com os estudantes). É importante destacar que estes estudantes não haviam estudado Termodinâmica. Moreira (2006, p. 25) estabelece estas ligações:

Por exemplo, para um aluno que já conhece a Lei da Conservação da Energia aplicada à energia mecânica, resolver problemas onde há transformação de energia potencial em cinética e vice-versa apenas corrobora o conhecimento prévio dando-lhe mais estabilidade cognitiva e talvez maior clareza. Mas se a Primeira Lei da Termodinâmica lhe for apresentada (não importa se em uma aula, em um livro ou em um moderno aplicativo) como a Lei da Conservação da Energia aplicada a fenômenos térmicos ele ou ela dará significado a essa nova lei na medida em que "acionar”o subsunçor Conservação da Energia, mas este ficará mais rico, mais elaborado, terá novos significados pois a Conservação da Energia aplicar-se-á não só ao campo conceitual da Mecânica mas também ao da Termodinâmica.

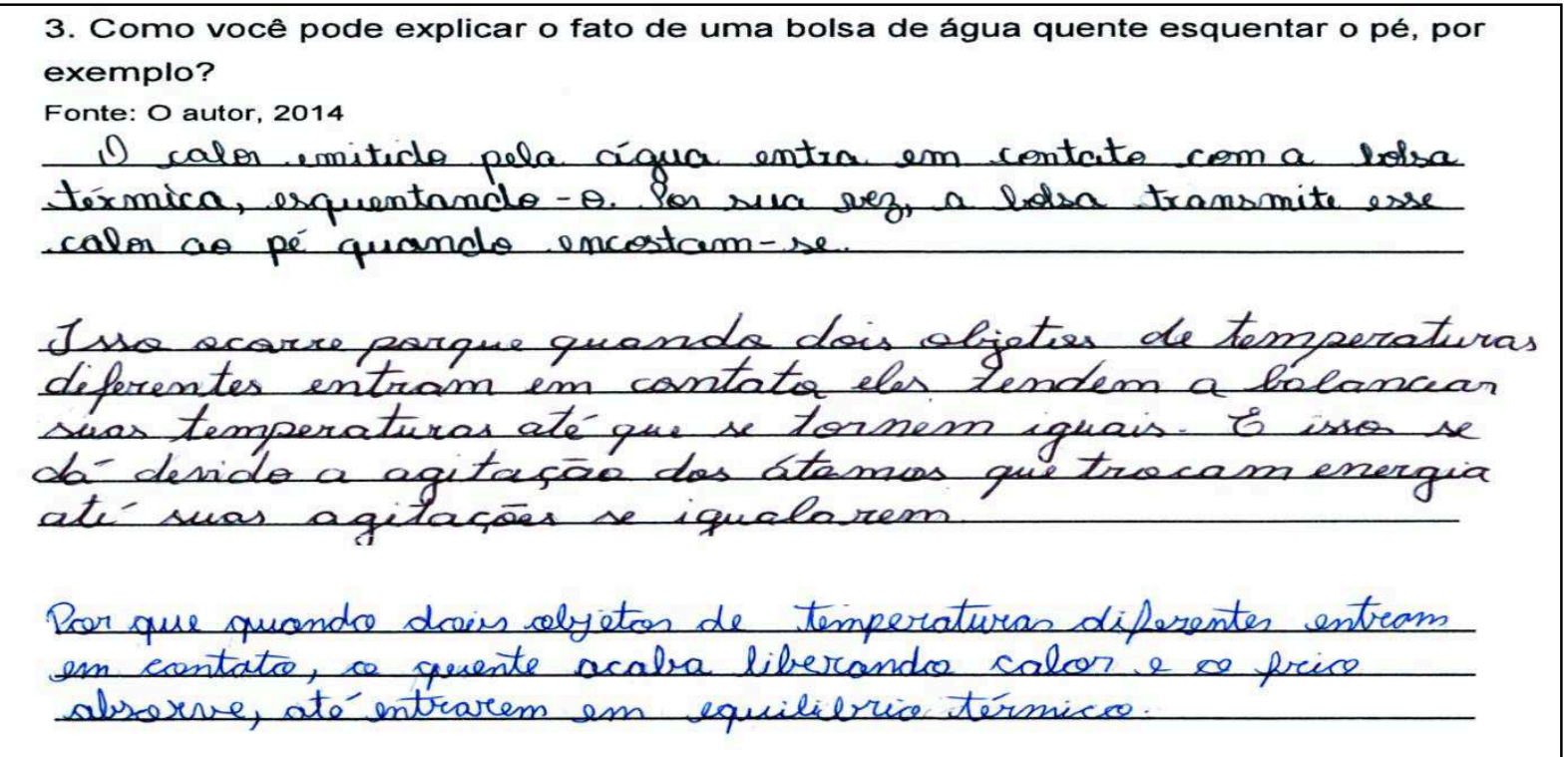

Fig. 10 - Respostas dadas à questão $3-E^{8}, E^{25}$ e $E^{33}$, respectivamente (Fonte: Os autores, 2015).

Finalmente, na questão número (6) que fazia referência a menor porção de massa que existe e da diferenciação entre sólido, líquido e gás, pode-se observar que os alunos mostraram ter os conhecimentos prévios para a aprendizagem dos conceitos de propagação de energia térmica. Na Fig. 11 são apresentadas algumas das respostas dos estudantes, mostrando a existência de subsunçores importante para a compreensão dos fenômenos da Termodinâmica. Observa-se que o estudante $\mathrm{E}^{5}$ faz a representação dos sólidos, líquidos e gases através de um desenho de suas moléculas.

Tendo como objetivo principal investigar as implicações do uso de simulações vinculadas às atividades experimentais na aprendizagem significativa dos estudantes no tópico transferência de energia térmica, no $2^{\circ}$ ano do Ensino Médio, foi possível, por meio das atividades realizadas, perceber que os estudantes estavam predispostos para trabalhar com as atividades 
experimentais e as simulações, realizando as atividades com entusiasmo e demonstrando interesse. Na sequência, são expostos os resultados alcançados por meio do desenvolvimento dos objetivos específicos.

O primeiro objetivo: Verificar os conhecimentos prévios dos estudantes relacionados à transferência de energia térmica, bem como suas aplicações em situações do cotidiano - foi alcançado através da realização do questionário semiestruturado. Por meio dele, foi possível verificar que os estudantes apresentavam algumas noções de propagação da energia térmica, principalmente a condução e a radiação, porém não diferenciavam calor e temperatura, o que para muitos significavam sinônimos. Por este motivo, o professor/pesquisador inicialmente estabeleceu a diferenciação destes dois conceitos, através de explicação oral dialogada.

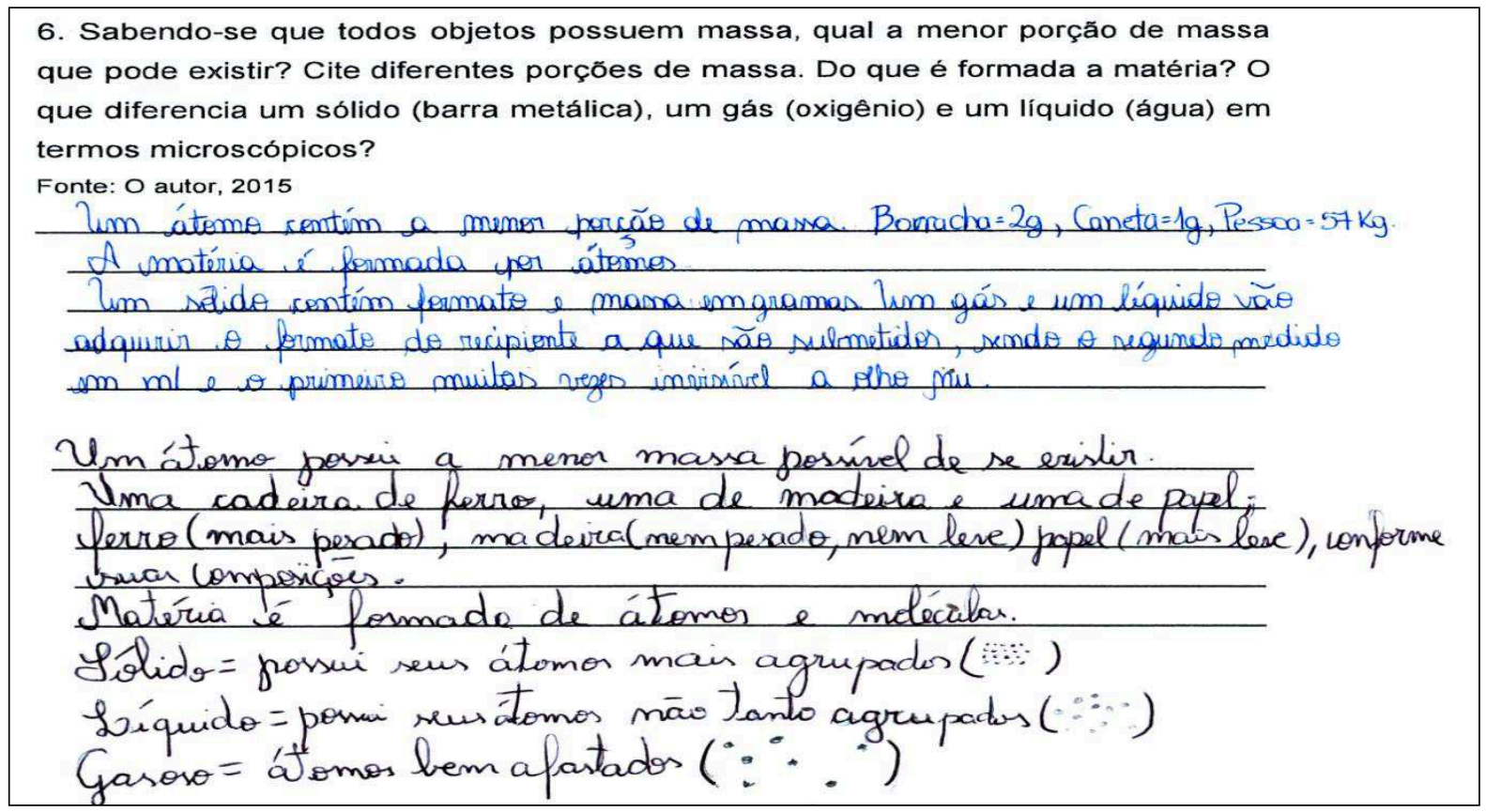

Fig. 11 - Respostas da questão $6-E^{5}$, $E^{6}$ respectivamente (Fonte: Os autores, 2015).

O segundo objetivo - Desenvolver o conteúdo de transferência de energia térmica por meio da integração entre as atividades experimentais e as simulações computacionais durante as aulas de Física no $2^{\circ}$ ano do Ensino Médio - foi atingido com as atividades experimentais e computacionais realizadas durante a intervenção pedagógica. Esses recursos possibilitaram aos estudantes a verificação dos fenômenos que muitas vezes observam no seu cotidiano, bem como a diferenciação entre as três formas de transferência de energia térmica e, a existência concomitante delas.

Já o terceiro objetivo: Investigar se as atividades desenvolvidas são potencialmente significativas para a aprendizagem dos alunos sobre elementos importantes da Termologia (formas de transferência de energia térmica) - foi possível verificar no geral, tanto nos questionários das atividades experimentais e computacionais, quanto nos mapas conceituais, as relações das respostas e dos conceitos abordados neste conteúdo. Algumas falas dos estudantes durante 
as aulas, transcritas das gravações para o diário de bordo da pesquisadora, são indícios que convergem para a aprendizagem significativa: "agora entendo o porquê das lajotas parecerem mais frias e o piso de madeira mais quente!’. “Ah!!!! Os coletores solares têm que ser sempre pintados de preto opaco, assim absorvem mais a energia do Sol, que é principalmente por radiação!!”. Ausubel (2003) destaca em sua teoria, que a linguagem pode determinar ou refletir as operações mentais que se estabelecem para a aquisição de conceitos mais abstratos ou de ordem superior.

Ao final da pesquisa, pode-se inferir que as atividades experimentais e as simulações computacionais podem constituir-se em um material potencialmente significativo para o trabalho do professor, visando a aprendizagem significativa dos estudantes. Ao final das atividades propostas os alunos demonstraram a vontade de que o trabalho dos demais conteúdos da Física do $2^{\circ}$ ano do Ensino Médio seja com atividades experimentais e simulações. Moreira (2011) destaca ser fundamental que o aprendiz apresente predisposição para aprender e que o material seja potencialmente significativo, para a ocorrência da aprendizagem significativa.

\section{Caminhos futuros}

Com este trabalho busca-se, além da formação profissional, contribuir para a elaboração de uma produção técnica, colocando em prática os conhecimentos adquiridos no Mestrado, material esse, que possa ser utilizado por outros professores em sua prática pedagógica. Durante as atividades realizadas nesta intervenção pode-se perceber o envolvimento, a predisposição dos estudantes durante as atividades computacionais (AC) e atividades experimentais (AE) propostas, o que já é uma das condições para a ocorrência da aprendizagem significativa. Conforme Ausubel (2003) os fatores cognitivos e de motivação interpessoal influenciam no processo de aprendizagem de forma concomitante.

Ao concluir a pesquisa, a primeira autora deste estudo sente-se desafiada e motivada a continuar integrando as simulações computacionais com as atividades experimentais em sua prática pedagógica. Espera-se que as atividades experimentais integradas com as simulações computacionais passem a fazer parte do cotidiano da sala de aula, em instituições de diferentes esferas, proporcionando ao estudante uma nova forma de aprender, aumentando a predisposição, desenvolvendo habilidades como observação, análise, tomada de decisões e raciocínio lógico.

As atividades experimentais, reais e virtuais são uma possibilidade para envolver os alunos e motivá-los, bem como, uma alternativa para sair das aulas tradicionais centradas em quadro, giz e livros. As atividades experimentais (reais e virtuais) trabalhadas integradas podem romper com o formalismo existente na estrutura curricular das escolas onde, conforme Moreira (2006), os conteúdos estão listados em um programa que é seguido linearmente, sem idas e voltas, ou como se os aspectos mais importantes devessem ficar para o final. Estas idas e voltas ao trabalhar os conteúdos em sala de aula, de acordo com Moreira (2006) são importantes para 
a reconciliação integradora, e nesta pesquisa aconteceram quando os mesmos conceitos foram abordados de diferentes formas, durante as atividades experimentais e as computacionais.

Da mesma forma, o autor ressalta que a maioria dos livros didáticos também é organizada desta forma linear e cronológica, começando do mais simples e terminando com o mais complexo. $\mathrm{O}$ autor destaca que para a aprendizagem significativa ser facilitada, o aprendiz deve ter uma visão inicial do todo, do que é importante para, então, diferenciar e reconciliar significados, critérios, propriedades e categorias. E essa organização linear não promove a diferenciação progressiva e a reconciliação integradora.

Portanto, a integração entre atividades experimentais e simulações computacionais pode contribuir para a aprendizagem significativa dos estudantes. Para trabalhos futuros, seria interessante a utilização da experimentação e simulação também em outras áreas do conhecimento, como a Química, Matemática e Biologia, procurando promover a interdisciplinaridade e permitindo que os estudantes, principalmente, na Educação Básica, participem ativamente da construção do seu conhecimento. Este é um desafio a cada profissional da educação, nas mais diversas áreas que, como os desta pesquisa, não concebem a escola na era pós moderna, que Baumann (2000) definiu como modernidade líquida, igual à escola de dois séculos atrás. No contexto pós moderno deve-se pensar a escola e a aprendizagem como um rizoma, onde as redes e as conexões entre os saberes, os alunos e a escola devem existir verdadeiramente.

\section{Agradecimentos}

Agradecemos aos avaliadores do presente artigo pelos comentários e sugestões apresentadas, contribuindo para a clareza e o enriquecimento do texto. Agradecemos também ao Colégio Franciscano São José por disponibilizar turmas para a aplicação da pesquisa.

\section{Referências bibliográficas}

ARANTES, A. R.; MIRANDA, M. S; STUDART, N. Objetos de aprendizagem no ensino de física: usando simulações do PhET. Física na Escola, São Paulo, v. 11, n. 1, 2010.

ARAÚJO, I. S.; VEIT, E. A.; MOREIRA, M. A. Modelos computacionais no ensino-aprendizagem de física: um referencial de trabalho. Investigações em Ensino de Ciências, v. 17, p. 341-366, 2012.

ARAÚJO, M. S. T.; ABIB, M. L. V. S. Atividades experimentais no ensino de Física: diferentes enfoques, diferentes finalidades. Revista Brasileira de Ensino de Física, São Paulo, v. 25, n. 2, p. 176-194, 2003.

AUSUBEL, D. P. A Aprendizagem significativa: a teoria de David Ausubel. São Paulo: Moraes, 1982. 250p. 
AUSUBEL, D. P. Aquisição e Retenção de Conhecimentos: Uma perspectiva cognitiva. 1. ed. Lisboa: Paralelo Editora Ltda. 2003. 220p.

BAUMANN, Z. Modernidade Líquida. Tradução: Plínio Dentzien. Rio de Janeiro: Jorge Zahar Editor, 2000.

BORGES, A. T. Novos rumos para o laboratório escolar de ciências. Caderno Brasileiro do Ensino de Física, v. 19, n. 3, p. 291-313, 2002.

BRANDÃO, R.V.; ARAUJO, I. S.; VEIT, E. A. A modelagem científica de fenômenos físicos e o ensino de Física. Física na Escola, São Paulo, v. 9, n. 1, 2008.

BRASIL. Ministério da Educação. Secretaria de Educação Média e Tecnológica. Parâmetros Curriculares Nacionais: Ensino Médio. Brasília, 1999.

BUCUSSI, A. A. Introdução ao Conceito de Energia. Textos de apoio ao professor de física. Porto Alegre, 2007.

DENZIN, N. K.; LINCOLN, Y. S. Introdução: a disciplina e a prática da pesquisa qualitativa. Planejamento da pesquisa qualitativa: teorias e abordagens. Porto Alegre: Artmed, 2006.

DORNELES, P. F. T. Integração entre atividades computacionais e experimentais como recurso instrucional no ensino de eletromagnetismo em física geral. 2010. 367f. Tese (Doutorado em Ciências) - Instituto de Física, UFRGS, Porto Alegre.

DORNELES, P. F. T., ARAUJO, I. S., VEIT, E. A. Simulação e modelagem computacionais no auxílio à aprendizagem significativa de conceitos básicos de eletricidade: Parte I - circuitos elétricos simples. Revista Brasileira de Ensino de Física, São Paulo, v. 28, n. 4, p. 487-496, 2006.

DUTRA, Í. M. et al. Uma base de dados para compartilhamento de experiências no uso de mapas conceituais no acompanhamento de processos de conceituação. Novas tecnologias na Educação, Porto Alegre, v. 4, n. 2, p. 124-138, 2006.

HEIDEMANN, L. A. Crenças e atitudes sobre o uso de atividades experimentais e computacionais no ensino de física por parte de professores do ensino médio. 2011, 135f. Dissertação (Mestrado em Ensino de Física) - Instituto de Física, UFRGS, Porto Alegre.

LÉVY, P. As tecnologias da inteligência: o futuro do pensamento na era da informática. Tradução: Carlos Irineu da Costa. Rio de Janeiro: Original, 2008.

MEDEIROS A.; MEDEIROS C. F. Possibilidades e limitações das simulações computacionais no ensino de Física. Revista Brasileira de Ensino de Física, São Paulo, v. 24, n. 2, p. 430-442, 2002 . 
MOREIRA, M. A. Uma abordagem Cognitiva ao Ensino de Física: A teoria de aprendizagem de David Ausubel como sistema de referência para a organização do ensino de ciências. Porto Alegre: UFRGS, 1983.

Aprendizagem significativa: a teoria de David Ausubel. São Paulo: Centauro, 2001. 87p.

. Mapas conceituais e diagramas V. Porto Alegre: Ed. do autor, 2005. 68p.

. Organizadores prévios e aprendizagem significativa. Revista Chilena de Educación Científica, Chile, v. 7, n. 2, p. 23-30, 2008.

Aprendizagem Significativa: a teoria e textos complementares. São Paulo: Livraria da Física, 2011.

. Aprendizagem significativa: da visão clássica à visão crítica. In: ENCONTRO INTERNACIONAL SOBRE APRENDIZAGEM SIGNIFICATIVA, 5, Madrid. Anais... Madri, 2006. Disponível em: <http://www.if.ufrgs.br/ moreira/visaoclasicavisaocritica.pdf>. Acesso em: 15 jul. 2015.

MOREIRA, M. A.; OSTERMANN, F. Teorias Construtivistas. Textos de Apoio ao Professor de Física, n.10. Porto Alegre: UFRGS, 1999. 83p.

Physlets e Open Source Physics para professores e estudantes Portugueses. Revista Lusófona de Educação, Portugal, v. 25, p. 59-72, 2013.

SILVA, O. H.; LABURÚ, C. E.; NARDI, R. Reflexões para subsidiar discussões sobre o conceito de calor na sala de aula. Caderno Brasileiro de Ensino de Física, v. 25, n. 3, 2008.

SUART, R. C.; MARCONDES, M. E. R. Atividades experimentais investigativas: habilidades cognitivas manifestadas por alunos do Ensino Médio. In: ENCONTRO NACIONAL DE ENSINO DE QUÍMICA, 2008, Curitiba. Atas...

TAVARES, R. Construindo mapas conceituais. Ciências \& Cognição, Rio de Janeiro, v. 12, p. 72-85, 2007.

YOUNG, H.; FREEDMAN I. Física II: Termodinâmica e Ondas. São Paulo: Addison Wesley, 2008.

ZACHARIAS, Z; ANDERSON, O. R. The effects of an interactive computer-based simulation prior to performing a laboratory inquiry-based experiment on students' conceptual understanding of physics. American Journal of Physics, Melville, v. 71, n. 6, p. 618-629, 2003. 